\title{
Determinants of Strategic Plan Implementation at Co-Operative Bank of Kenya
}

\author{
Winnie Wairimu Mwangi* $\quad$ Prof. Isaac Ochieng Thomas Gakobo \\ Laikipia University, Kenya
}

\begin{abstract}
The intense competition facing the banking sector has placed greater pressure on them to seek ways to achieve a sustained competitive advantage. In order to remain relevant in the market, commercial banks have to continually review their strategic plans and formulate new competitive strategies to suit emerging trends in the market. Well thought strategic planning and effective implementation can be used as a tool for achieving banking industry goals, it is therefore important to critically examine the determining factors of good plan implementation. The main aim of this study was to establish the determinants of strategic plan implementation in the Banking Sector, a case of Co-operative Bank of Kenya. The study sought to examine the influence of transformational leadership, stakeholder involvement and resource allocation on strategic plan implementation at Co-operative bank of Kenya. The study adopted a descriptive research design. The target population of the study was 210 management employees working in the Co-operative bank head office branch. Stratified and simple random sampling was used to select $50 \%$ of the management staff. This study relied on primary data. The study collected primary data by use of questionnaires that comprised of open and closed ended questionnaires. SPSS was used to produce frequencies, descriptive and inferential statistics which was used to derive conclusions and generalizations regarding the population. The study findings indicated that the bank had put into place mechanisms to ensure that strategy plan implementation was a success by having transformational leaders, involving all the stakeholders and ensuring the resources allocated are efficient for the process. The study concluded that transformational leadership, stakeholder involvement and resource allocation were statistically significant in explaining strategic plan implementation. The study recommends that the leadership of any organization should always stay visionary as this would help in steering the organization to attaining both its short and long-term goals. The bank should ensure that their policy manual is maintained and updated regularly, the institution also need to have in place policies to help guide the firm to overcome dynamic changes in the sector.
\end{abstract}

Keywords: Strategic Plan Implementation, Leadership, Stakeholder Involvement, Co-operative Bank

DOI: $10.7176 / \mathrm{EJBM} / 11-32-07$

Publication date: November $30^{\text {th }} 2019$

\section{Introduction}

Companies' success factors is dependent on Strategic implementation, addressing the who, where, when, and how of reaching the desired goals and objectives. It focuses on the entire organization. Implementation occurs after environmental scans, SWOT analyses, and identifying strategic issues and goals. To help an Organization to reach its goals, it involves assigning individuals to tasks and timelines (Kristie, 2018). According to Pearce, Robinson and Amital (2007), the definition of strategy is the direction and scope of an organization over the long term, which achieves advantage in changing environment through its configuration of resources and competences with the aim of fulfilling stakeholder expectations. On the other hand, strategic management is the set of decisions and actions that result in the formulation and implementation of plans designed to achieve a company objective. Strategies exist at corporate, business or operational level. Successful business strategy depends to a large extent on decisions that are taken or activities that occur at the operational level. Functional managers play a key role in ensuring the organization achieves its objectives. Corporate and business level managers concentrate their attention on doing the right things, managers at the functional level center ensures things are done right. Thus, they address issues such as efficiency and effectiveness of production, the quality of customer service among others.

The intense competition facing the banking sector has placed greater pressure on them to seek ways to achieve a sustained competitive advantage. Awward (2008) suggests that in order to remain relevant in the market, commercial banks have to continually review their strategic plans and formulate new competitive strategies to suit emerging trends in the market. However, the best formulated strategies may fail to produce superior performance for the firm if they are not successfully implemented (Noble, 1999). Organizational culture is created when there is a set of believers and values that are shared among employees of an organization (Austin, 2002). The organizational culture influences strategy implementation because it is the bedrock on which values, formal norms affecting goals and objectives are anchored (Zona and Zattoni, 2007), and a successful firm's strategy must be favorably aligned with the external environment (Ndung'u, Machuki \& Murerwa, 2014).

Strategy implementation is even more important in turbulent times. The environment in which 
organizations operate is increasingly dynamic or even turbulent (Volberda, 1996; D’Aveni, 1994). Developments such as the globalization of markets, rapid technological change and deregulation of industries, a shift of organizations and the increasing aggressiveness of competition have radically altered the competitive rules during the 1990s and beyond (Volberda, 1996). Short periods of competitive advantage, punctuated by frequent disruptions, have replaced the long and stable periods of the past in which organizations could achieve a sustainable competitive advantage (Volberda, 1996; D'Aveni, 1994). These environmental developments have resulted in strong pressures for strategic change (Baden-Fuller \& Volberda, 1997; Thomas, 2002) to maintain a 'fit' with these changing environments. In turbulent environments, the ability to implement new strategies quickly and effectively may well mean the difference between success and failure for an organization (Drazin \& Howard, 1984; Hauc \& Kovac, 2000). Even slight delays can prove critical in highly competitive and dynamic environments. Consequently, strategy implementation is a key concern in the management of strategic change (Thomas, 2002). However, well-formulated strategies only produce superior performance for an organization when they are successfully implemented (Bonoma, 1984).

The best made strategies are worthless if they cannot be implemented successfully (Schilit, 1987). Thus, strategic success not only requires an appropriate strategy but also requires that the strategy is implemented successfully and timely (Hussey, 1996). Furthermore, strategies that fail to be implemented can be very costly, both in terms of formulation costs and foregone benefits (Nutt, 1998). The biggest challenge in strategic change is however the phase after planning, the successful implementation of the strategy that is needed and developed. This study will deal with the issue of strategic plans implementation. As Olson, Slater and Hult (2005) say it, 'doing is harder than dreaming'. This study therefore sought to investigate the determinants of strategic plan implementation in the banking sector with reference to Co-operative Bank of Kenya.

\subsection{Statement of the Problem}

It's no longer a secret that most companies struggle with strategy implementation. Most of the change efforts fall short of the desired results. The losses are massive and senior leaders should realize that implementation is at least half of the leadership challenge when it comes to improving performance via strategic change. Too frequently, however, the leaders seek solutions in the wrong place.

The task of implementing a strategy is critical to the survival of an organization and enhancing its performance in a competitive industry (Atkinson, 2006). It is noted that strategy implementation is a key process in achieving institutional goals and objectives and heightening the organizational performance (Allio, 2005). The drive for institutions to adapt to the highly dynamic and competitive environment has led to refocusing of strategies so as to improve performance (Huang, 2012). The influence of strategy implementation on organizational performance continues to be singled out as important in research and practice (Gaya, Struwig \& Smith, 2013).

For many years, there has been constant emphasis on strategy formulation and inadequate emphasis on strategy implementation (Shamila, Muhammad \& Sohail, 2016; Nnamani, Ejim \& Ozobu, 2015 and Akinyele \& Fasogbon, 2007). This emphasis on the plan and little or none on the implementation has been the cause of under-performance in organizations. Noble (1999) asserted that most institutions' best-conceived strategies fail to generate premium performance due to poor implementation. Unless the desired financial and non-financial results dictated by an institutional strategy are achieved, the institution will be incapable of exploiting the future opportunities and combating threats effectively (Hrebiniak, 2006).

Several studies have been done on strategies and strategy implementation in organizations in Kenya; Karimi (2015) carried out a study to determine influence of organization culture on strategy implementation at Technical University of Mombasa and Pwani University. The study focused mainly on influence on behaviour norms on strategy implementation. It did not cover the determinants factors in the implementation phase at co-operative bank. Nyaga (2012) on the other hand did a study on Strategy implementation as a key success factor in mobile telecommunications in Kenya. This study focused on a different context and concept from what the current study seeks to cover. Muchai (2011) studied the impact of corporate culture in strategy implementation. His study mainly captured the extent to which East African Breweries culture influences their strategy and its implementation. The study focused on different context and concept from what the current study seeks to cover. The study also looked at one variable which is organization culture while the current study will look into three variables that influence strategic plan implementation at co-operative bank of Kenya. Whereas there have been research studies on strategy implementation undertaken in many sectors, few have been carried out to establish the determinants of strategic plan implementation at commercial banks with a special focus on Co-operative bank of Kenya. Therefore, this study sought to fill this gap by examining the determinants of strategic plan implementation at Co-operative bank of Kenya.

\subsection{Purpose of the Paper}

The purpose of this study was to investigate the determinants of strategic plan implementation in the banking 
sector with reference to Co-operative Bank of Kenya.

\subsection{Objectives of the Study}

i. To examine the extent to which transformational leadership influences strategic plans implementation at Co-Operative Bank of Kenya

ii. To assess the extent to which stakeholder involvement influence strategic plans implementation at CoOperative Bank of Kenya.

iii. To evaluate the extent to which resources allocation influences implementation of strategic plans in CoOperative Bank of Kenya

\section{Literature Review}

Schaap (2012) study's findings revealed that consensus is vital in the implementation process. The study also indicated that frequent communication up and down the organization structure enhances strategic consensus through the fostering of shared attitudes and values. According to the study, an organization which ties rewards to the success of the strategy employed is rewarded with higher levels of organizational performance and concluded that strategy implementation plans must be clearly developed, indicating particular tasks for individuals, with clear-cut time frames, and identifying the people responsible for task completion.

Rajasekar's (2014) study on the service sector (electricity) in Sultanate of Oman on the factors affecting implementation of strategy found that leadership is by far the most important factor influencing successful implementation strategy in the service sector, followed by organization culture, organization structure, with information systems the least important. Interestingly, majority prioritized business ethics to successful implementation of strategy, showing that to the majority the end does not justify the means.

Sila and Gichinga (2016) in a case study carried out at JKUAT Main Campus examined the role of strategic leadership in strategy implementation focusing on three main objectives that included the influence of organizational culture, strategic communication and strategic direction in strategy implementation. The research found out that strategic leadership plays a critical role in the effective implementation of strategy and recommended to strategic leaders in the public universities to drive the public universities to strategy implementation success if these universities were to survive and create wealth for all stakeholders.

Stakeholder involvement is a sub-process within the broader strategic planning and decision making process and key to effective stakeholder management (Mathur et al., 2008). Hitt et al (2001) emphasizes the benefits for the organization by describing stakeholder involvement as the confluence of corporate self-definition and occasional redefinition, impression management, and effective relationship maintenance with important partners. Sharma et al (2004) expand this perspective to include an organization's ability to develop collaborative relationships with a wide variety of economic and non-economic partners to find solutions to environmental problems. In the public sector, the OECD (2001) argues that engaging with citizens is a core element of good governance and benefits include improving the quality of policy making, and increasing accountability and transparency. As part of the responsibility toward good governance and to seek improved results, an organization needs to develop and maintain effective relationships with its primary stakeholders to ensure quality decision making (OECD, 2001).

Chepkoech and Waiganjo (2015) investigated the role of stakeholders in the implementation of strategic change in commercial banks in Kenya with a case study of National Bank of Kenya. This study adopted a descriptive research design. The target population for this study consisted of 120 staff working at all levels of management at NBK branches in Nairobi's Central Business District where a sample was selected using stratified sampling based on the management level in the Bank. This study collected primary using questionnaires. A pilot study was conducted to test the viability of the intended research. The primary data gathered were coded and analysed with the help of SPSS. The study found out that customer's preferences and tastes are key factors affecting the implementation of strategic change and that customers provide the indispensable influence to the bank in terms of competitive advantage, revenue and profits, employees are involved in the change management process need to be adequately trained. The study recommends that there needs to be stakeholder involvement in all stages of planning and implementation to bring a sense of ownership by all parties so that they can feel the strategy has not been forced on them and customers should be involved in the implementation of strategic change because they are the key stakeholders.

Sufficient resources are another crucial factor in strategy implementation. The lack of resources, on the other hand, may lead to the failure of strategy implementation. For one, implementing strategy, in most cases, take more time than expected or planned beforehand (Schaap, 2012). Porter (2005) suggests that the board members sometimes underestimate the time needed to complete a strategy implementation. Time is pressured even more if priorities are not set correctly. It should therefore be clear to all employees involved in the implementation are of most priority for execution. This includes implementation activities but also regular work and other projects. If priorities are not defined properly, it could either cause loss of attention for the strategy 
implementation or loss of attention for the regular work and other projects. Both could lead to problems in the organization.

Abok (2015) investigated the factors affecting organizational performance with reference to resource allocation. Her study revealed that strategic resource allocation measures were slowly being adopted by organizations, inhibiting optimum performance of these organizations. The study focused on the financial factors affecting effective implementation of strategies. Gaya et al. (2013) in his assessment of the determinants of strategy implementation at the Kenya Sugar Board found out that lack of proper strategy planning affected resource allocation at the Board. This was manifested by planning several strategies at once, which caused a strain in allocated resources leading to poor implementation of strategies. The study also revealed that the Board focused much on allocation of financial resources at the strategy planning stage, neglecting the role of nonfinancial resources such as human resources in strategy implementation resulting to under performance of the organization.

\section{Methodology}

The study adopted descriptive survey design. Descriptive research designs help provide answers to the questions of who, what, when, where, and how associated with a particular research problem; a descriptive study cannot conclusively ascertain answers to why. Descriptive research was used to obtain information concerning the current status of the phenomena and to describe "what exists" with respect to variables or conditions in a situation (Creswell, 2013). The target population of the study comprised of all the management employees at Cooperative Bank Head office branch. The study focused on 210 staff stratified into the senior, middle management and lower management level.

This study utilized the stratified random sampling technique. This was because the populations under study can easily be divided into relevant and significant strata based on management staff. With stratified random sampling one can ensure that each of the strata is represented proportionally within a sample. Moreover, the stratified random sampling technique chosen for this study will increase a sample's statistical efficiency, provide adequate data for analyzing the various subpopulations or strata and also enable different research methods and procedures to be used in different strata (Coopers and Schindler, 2011). Kothari (2012) assert that 10\% of the accessible population is an adequate sample where one is using a descriptive studies design. Since the research assumes a descriptive survey design, the researcher examined a sample of 50\%. Therefore, from each stratum managers were selected to make a sample of 105 management employees.

The study used likert scale questionnaires as a major tool for data collection. The questionnaires were dropped to respondents' offices by both the researcher and 2 research assistants, and later collected after one week. This study was conducted in a normal setting and the research questionnaires were coded to exclude the names of the respondents hence protecting their anonymity. Consent of the respondents was sought and an assurance of confidentiality affirmed. All the questionnaires used in data collection were locked in undisclosed location and destroyed after they have served their purpose. Data was collected, coded and analyzed using SPSS version 20.0. The findings were presented in form of tables and pie charts and discussions and interpretation of the same given.

\section{Results and Discussions}

\subsection{Response Rate}

The study initially targeted 105 respondents. However the questionnaires that were dully filled, returned on time and used for data analysis were 89 . The study therefore had a response of $85 \%$, according to Mugenda \& Mugenda (2003).Willimack (2002) a suitable response should be $50 \%$ - $60 \%$ or more of the intended sample population. The response rate was therefore considered satisfactory for data analysis.

\subsection{Descriptive Statistics}

Based on primary data the study conducted descriptive statistics including frequencies, percentages and means. This was conducted to find out how the respondents agreed or disagreed with the statements in the questionnaire.

\subsubsection{Transformational Leadership and Strategic Plan Implementation}

The study sought to examine the extent to which transformational leadership influences strategic plans implementation at Co-Operative Bank of Kenya. Table 1 shows that $74.1 \%$ of the respondents agreed that the leadership in the institution had concrete vision for the future of the institution; another $74.1 \%$ agreed that the leadership in the institution offered strategic decisions in strategy implementation and $80.9 \%$ of the respondents agreed that leaders in the institution "practiced what they preached". In addition, $60.6 \%$ of the respondents agreed that leadership at the bank inspired their subordinates, 68.5\% agreed that bank leadership influenced workers motivation and $74.1 \%$ agreed that the leadership rewarded employees based on the performance. Finally, $55.1 \%$ of the respondents agreed that different opinions were tolerated by the institution leadership and $67.4 \%$ agreed that the state of the leadership in the institution was healthy to promote organizational success. The mean 
score for responses for this section was 3.75 which indicates that majority of the respondents agreed that transformational leadership was a key determinant of strategic plan implementation in Co-operative bank. The findings imply that the strategy plans must receive approval and support from top management before it can be implemented. Top management must be willing to become involved and to allocate valuable resources to the implementation effort. As the strategic plan span divisional boundaries and affect many stakeholders in an organization, senior executives need to mediate between various interest groups to resolve political conflicts when necessary and ensure people work as a team to enhance successful implementation. The study findings are in line with those of Chepkirui (2012) who examined the role of strategic leadership in the strategy implementation in Agricultural Development Corporation (ADC) in Kenya and found that strategic leadership was very effective implementation of strategy. According Chepkirui, strategic leadership stirs commitment among people within the organization to embrace change and implement strategies intended to achieve the strategic vision. The study enumerated the role of leadership in strategy implementation determination of strategic direction, building an organization, shaping effective organizational culture, effective management of organization's resource portfolio, enforcement of ethical compliance, communicating strategy, development of short-term objectives and operational plans.

Table 1: Responses on Transformational Leadership

\begin{tabular}{|c|c|c|c|c|c|c|c|}
\hline Statement & $\begin{array}{r}\text { Strongly } \\
\text { disagree }\end{array}$ & Disagree & $\begin{array}{l}\text { Not } \\
\text { sure }\end{array}$ & Agree & $\begin{array}{c}\text { Strongly } \\
\text { agree }\end{array}$ & Mean & $\begin{array}{c}\text { Std. } \\
\text { Deviation }\end{array}$ \\
\hline $\begin{array}{l}\text { The leadership in the institution has } \\
\text { concrete vision for the future of the } \\
\text { institution }\end{array}$ & $12.4 \%$ & $0.0 \%$ & $13.5 \%$ & $39.3 \%$ & $34.8 \%$ & 3.84 & 1.26 \\
\hline $\begin{array}{l}\text { The leadership in the institution } \\
\text { offers strategic decisions in strategy } \\
\text { implementation }\end{array}$ & $12.4 \%$ & $0.0 \%$ & $13.5 \%$ & $39.3 \%$ & $34.8 \%$ & 3.84 & 1.26 \\
\hline $\begin{array}{l}\text { Leaders in the institution "practice } \\
\text { what they preach" }\end{array}$ & $12.4 \%$ & $0.0 \%$ & $6.7 \%$ & $44.9 \%$ & $36.0 \%$ & 3.92 & 1.245 \\
\hline $\begin{array}{l}\text { Leadership at the bank inspires their } \\
\text { subordinates }\end{array}$ & $12.4 \%$ & $6.7 \%$ & $20.2 \%$ & $30.3 \%$ & $30.3 \%$ & 3.6 & 1.32 \\
\hline $\begin{array}{l}\text { Bank leadership influences workers } \\
\text { motivation }\end{array}$ & $12.4 \%$ & $0.0 \%$ & $19.1 \%$ & $38.2 \%$ & $30.3 \%$ & 3.74 & 1.248 \\
\hline $\begin{array}{l}\text { The leadership rewards employees } \\
\text { based on the performance }\end{array}$ & $5.6 \%$ & $6.7 \%$ & $13.5 \%$ & $43.8 \%$ & $30.3 \%$ & 3.87 & 1.099 \\
\hline $\begin{array}{l}\text { Different opinions are tolerated by the } \\
\text { institution leadership }\end{array}$ & $12.4 \%$ & $20.2 \%$ & $12.4 \%$ & $38.2 \%$ & $16.9 \%$ & 3.27 & 1.304 \\
\hline $\begin{array}{l}\text { The state of the leadership in this } \\
\text { institution is healthy to promote } \\
\text { organizational success. }\end{array}$ & $5.6 \%$ & $0.0 \%$ & $27.0 \%$ & $30.3 \%$ & $37.1 \%$ & 3.93 & 1.074 \\
\hline Aggregate Score & $10.7 \%$ & $4.2 \%$ & $15.7 \%$ & $38.0 \%$ & $31.3 \%$ & 3.75 & 1.226 \\
\hline
\end{tabular}

\subsubsection{Stakeholder Involvement and Strategic Plan Implementation}

The study sought to assess the extent to which stakeholder involvement influence strategic plans implementation at Co-Operative Bank of Kenya. The study findings on Table 2 indicates that $75.2 \%$ of the respondents agreed that other stakeholders who were not directly employed in this institution were involved at relevant instances, $68.5 \%$ agreed that the vision of the institution was shared among the Key stakeholders from time to time and $75.2 \%$ agreed that there was a general constant communication among employees, management and other stakeholders. Seventy five point two (75.2) of the respondents agreed that identifying the needs and problems of the various groups leads to achieving the organizations goals, $82 \%$ agreed that involving stakeholder in implementation of strategic plan leads to success and $94.3 \%$ agreed that assuming responsibilities to plan by all members motivated them into achieving the organization goals. Finally, $87.7 \%$ of the respondents agreed that assessing the individual and collective actions greatly influenced effective strategy implementation. The aggregate mean score for project planning stands at 3.89 which imply that the respondents agreed stakeholder involvement was a key driver of strategic plan implementation in Co-operative Bank of Kenya. The findings imply that the organizations had well laid down strategy plan with clear vision and mission statements to help achieve the organizations goals and objectives, and this was done guided by all the stakeholders by conducting a stakeholder need analysis and then address their needs and requirements hence guiding the formulation of the strategic plan and its implementation. The study findings are in support of Chepkoech and Waiganjo (2015) who investigated the role of stakeholders in the implementation of strategic change in commercial banks in Kenya and found out that customer's preferences and tastes are key factors affecting the implementation of strategic change and that customers provide the indispensable influence to the bank in terms of competitive advantage, revenue and profits, employees are involved in the change management process need to be adequately trained. 
Table 2: Responses on Stakeholder Involvement

\begin{tabular}{|c|c|c|c|c|c|c|c|}
\hline Statement & $\begin{array}{l}\text { Strongly } \\
\text { disagree }\end{array}$ & Disagree & $\begin{array}{l}\text { Not } \\
\text { sure }\end{array}$ & Agree & $\begin{array}{c}\text { Strongly } \\
\text { agree }\end{array}$ & Mean & $\begin{array}{c}\text { Std. } \\
\text { Deviation }\end{array}$ \\
\hline $\begin{array}{l}\text { Other stakeholders who are not } \\
\text { directly employed in this institution } \\
\text { are involved at relevant instances }\end{array}$ & $6.7 \%$ & $0.0 \%$ & $18.0 \%$ & $64.0 \%$ & $11.2 \%$ & 3.73 & 0.914 \\
\hline $\begin{array}{l}\text { The vision of the institution is } \\
\text { shared among the Key stakeholders } \\
\text { from time to time }\end{array}$ & $5.6 \%$ & $5.6 \%$ & $20.2 \%$ & $49.4 \%$ & $19.1 \%$ & 3.71 & 1.025 \\
\hline $\begin{array}{l}\text { There is a general constant } \\
\text { communication among employees, } \\
\text { management and other stakeholders }\end{array}$ & $5.6 \%$ & $5.6 \%$ & $13.5 \%$ & $64.0 \%$ & $11.2 \%$ & 3.7 & 0.946 \\
\hline $\begin{array}{l}\text { Identifying the needs and problems } \\
\text { of the various groups leads to } \\
\text { achieving the organizations goals }\end{array}$ & $5.6 \%$ & $0.0 \%$ & $19.1 \%$ & $64.0 \%$ & $11.2 \%$ & 3.75 & 0.87 \\
\hline $\begin{array}{l}\text { Involving stakeholder in } \\
\text { implementation of strategic plan } \\
\text { leads to success }\end{array}$ & $5.6 \%$ & $0.0 \%$ & $12.4 \%$ & $44.9 \%$ & $37.1 \%$ & 4.08 & 1.003 \\
\hline $\begin{array}{l}\text { Assuming responsibilities to plan by } \\
\text { all members motivates them into } \\
\text { achieving the organization goals. }\end{array}$ & $5.6 \%$ & $0.0 \%$ & $0.0 \%$ & $64.0 \%$ & $30.3 \%$ & 4.13 & 0.894 \\
\hline $\begin{array}{l}\text { Assessing the individual and } \\
\text { collective actions greatly influence } \\
\text { effective strategy implementation }\end{array}$ & $5.6 \%$ & $0.0 \%$ & $6.7 \%$ & $50.6 \%$ & $37.1 \%$ & 4.13 & 0.968 \\
\hline Aggregate Score & $5.8 \%$ & $1.6 \%$ & $12.8 \%$ & $57.3 \%$ & $22.5 \%$ & 3.89 & 0.946 \\
\hline
\end{tabular}

\subsubsection{Resource Allocation and Strategic Plan Implementation}

The study sought to evaluate the extent to which resources allocation influences implementation of strategic plans in Co-Operative Bank of Kenya. Table 3 illustrates that $87.6 \%$ of the respondents agreed that resource allocation determined achievement of results, $88.7 \%$ agreed that budgeting influenced achievement of goals and $87.7 \%$ agreed that lack of human and physical resources affected realization of goals. In addition, $94.4 \%$ of the respondents agreed that leadership commitment influenced attainment of results, $80.9 \%$ agreed that monitoring resources influenced attainment of results and $82 \%$ agreed that funds allocation enhanced achievement of sufficient results. In furtherance, $75.3 \%$ of the respondents agreed that use of budget as an evaluation and control tool ensured meeting of deadlines, $68.5 \%$ agreed that they had implemented IT effectively to facilitate strategy implementation and $87.7 \%$ agreed that Information Technology infrastructure facilitated achievement of business objectives. The aggregate mean score of responses for this section was 4.13 which indicates that majority of the respondents agreed that resource allocation was a key determinant of strategic plan implementation in Co-operative bank of Kenya. The findings imply that the organization must have the necessary resources including financial, human and technological infrastructure to ensure successful implementation of the plan. Results are in constitent with those of Abok (2015) who investigated the factors affecting organizational performance with reference to resource allocation and revealed that strategic resource allocation measures were slowly being adopted by organizations, inhibiting optimum performance of these organizations. Similarly, Gaya et al. (2013) in his assessment of the determinants of strategy implementation at the Kenya Sugar Board found out that lack of proper strategy planning affected resource allocation at the Board. This was manifested by planning several strategies at once, which caused a strain in allocated resources leading to poor implementation of strategies. The study also revealed that the Board focused much on allocation of financial resources at the strategy planning stage, neglecting the role of non-financial resources such as human resources in strategy implementation resulting to under performance of the organization. 
Table 3: Responses on Resource Allocation

\begin{tabular}{|c|c|c|c|c|c|c|c|}
\hline Statement & $\begin{array}{l}\text { Strongly } \\
\text { disagree }\end{array}$ & Disagree & $\begin{array}{l}\text { Not } \\
\text { sure }\end{array}$ & Agree & $\begin{array}{l}\text { Strongly } \\
\text { agree }\end{array}$ & Mean & $\begin{array}{c}\text { Std. } \\
\text { Deviation }\end{array}$ \\
\hline $\begin{array}{l}\text { Resource allocation determines } \\
\text { achievement of results }\end{array}$ & $0.0 \%$ & $0.0 \%$ & $12.4 \%$ & $43.8 \%$ & $43.8 \%$ & 4.31 & 0.684 \\
\hline $\begin{array}{l}\text { Budgeting influences achievement } \\
\text { of goals }\end{array}$ & $0.0 \%$ & $0.0 \%$ & $11.2 \%$ & $62.9 \%$ & $25.8 \%$ & 4.15 & 0.594 \\
\hline $\begin{array}{l}\text { Lack of human and physical } \\
\text { resources affect realization of goals }\end{array}$ & $0.0 \%$ & $0.0 \%$ & $12.4 \%$ & $12.4 \%$ & $75.3 \%$ & 4.63 & 0.697 \\
\hline $\begin{array}{l}\text { Leadership commitment influences } \\
\text { attainment of results }\end{array}$ & $5.6 \%$ & $0.0 \%$ & $0.0 \%$ & $31.5 \%$ & $62.9 \%$ & 4.46 & 0.966 \\
\hline $\begin{array}{l}\text { Monitoring resources influences } \\
\text { attainment of results }\end{array}$ & $5.6 \%$ & $0.0 \%$ & $13.5 \%$ & $24.7 \%$ & $56.2 \%$ & 4.26 & 1.072 \\
\hline $\begin{array}{l}\text { Funds allocation enhances } \\
\text { achievement of sufficient results }\end{array}$ & $5.6 \%$ & $0.0 \%$ & $12.4 \%$ & $30.3 \%$ & $51.7 \%$ & 4.22 & 1.053 \\
\hline $\begin{array}{l}\text { Use of budget as an evaluation and } \\
\text { control tool ensures meeting of } \\
\text { deadlines }\end{array}$ & $12.4 \%$ & $5.6 \%$ & $6.7 \%$ & $61.8 \%$ & $13.5 \%$ & 3.58 & 1.176 \\
\hline $\begin{array}{l}\text { We have implemented IT } \\
\text { effectively to facilitate strategy } \\
\text { implementation }\end{array}$ & $5.6 \%$ & $6.7 \%$ & $19.1 \%$ & $68.5 \%$ & $0.0 \%$ & 3.51 & 0.854 \\
\hline $\begin{array}{lr}\text { Information } & \text { Technology } \\
\text { infrastructure } & \text { facilitates } \\
\text { achievement of business objectives }\end{array}$ & $5.6 \%$ & $0.0 \%$ & $6.7 \%$ & $56.2 \%$ & $31.5 \%$ & 4.08 & 0.944 \\
\hline Aggregate Score & $4.5 \%$ & $1.4 \%$ & $10.5 \%$ & $43.6 \%$ & $40.1 \%$ & 4.13 & 0.893 \\
\hline
\end{tabular}

\subsection{Correlation Test Results}

Table 4 displays the results of correlation test analysis between the dependent variable (Strategic plan implementation) and independent variables and also correlation among the independent variables themselves. Results indicated that there was a positive and significant relationship between strategic plan implementation and all the independent variables. This reveals that any positive change in transformational leadership, stakeholder involvement and resource allocation leads to improved strategic plan implementation.

The results indicated that there exist a positive and significant $(\mathrm{r}=0.740, \mathrm{p}<0.000)$ correlation between strategic plan implementation and transformational leadership. This reveals that any positive change in transformational leadership effectiveness led to improved strategic plan implementation. The findings imply that improved strategic plan implementation would be associated with effective transformational leadership in the organization.

The results also indicated that there exists a positive and significant $(r=0.837, p<0.000)$ correlation between strategic plan implementation and stakeholder involvement. This reveals that any positive change in stakeholder involvement effectiveness led to improved strategic plan implementation. The correlation between the variables indicates that improved strategic plan implementation would be associated with stakeholder involvement effectiveness as indicated by a positive correlation between the two variables.

Finally, the results indicated that there exist a positive and significant $(r=0.773, p>0.000)$ correlation between strategic plan implementation and resource allocation. This reveals that any positive change in resource allocation effectiveness led to improved strategic plan implementation. The findings imply that improved strategic plan implementation would be associated with effective and efficiency use of resources available in the organization and thus reporting successful implementation of the strategy and the system.

Table 4: Bivariate Correlation

\begin{tabular}{llc}
\hline Variable & & Strategy Implementation \\
\hline Transformational Leadership & Pearson Correlation & $.740^{* *}$ \\
& Sig. (2-tailed) & 0.000 \\
Stakeholder Involvement & Pearson Correlation & $.837^{* *}$ \\
& Sig. (2-tailed) & 0.000 \\
Resource Allocation & Pearson Correlation & $.773^{* *}$ \\
& Sig. (2-tailed) & 0.000 \\
\hline
\end{tabular}

\subsection{Regression Results}

Regression analysis was conducted to empirically determine whether transformational leadership, stakeholder 
involvement and resource allocation were significant determinants of strategic plan implementation. The results presented in the Table 5 indicate that the goodness of fit for the regression of independent variables and strategic plan implementation was satisfactory. An R squared of 0.745 indicates that $74.5 \%$ of the variations in strategic plan implementation in Co-operative bank are jointly accounted for by the variations in transformational leadership, stakeholder involvement and resource allocation. From this it can thus be asserted that the variables adopted in the study jointly explained a greater proportion of the variation in strategic plan implementation at cooperative bank and that the unexplained variation is small.

\section{Table 5: Regression Model Fitness}

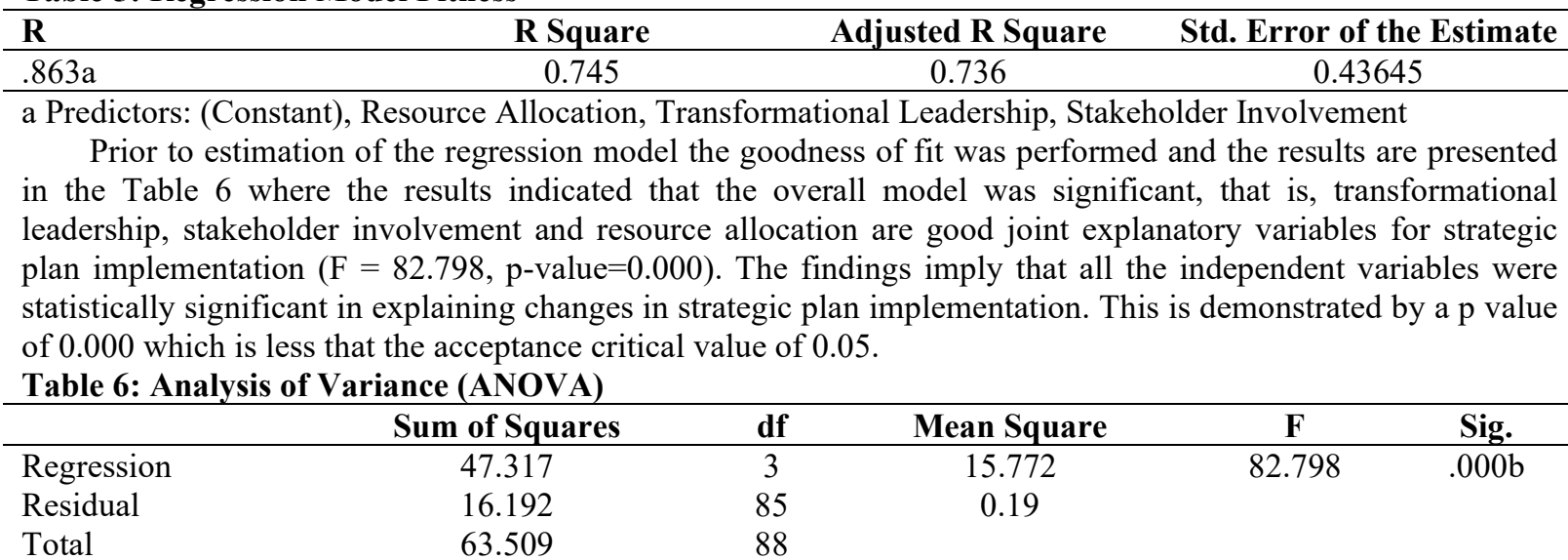

a Dependent Variable: Strategy Implementation

b Predictors: (Constant), Resource Allocation, Transformational Leadership, Stakeholder Involvement

Table 7 displays the regression coefficients of the independent variables. Regression results indicated that the relationship between transformational leadership and strategic plan implementation was positive and significant (beta $=0.154, \mathrm{p}$ value, 0.026). This implies that an increase in transformational leadership effectiveness by 1 unit leads to improved strategic plan implementation at a rate of 15.4 percent.

Results further indicate that stakeholder involvement and strategic plan implementation had a positive and significant relationship (beta $=0.545 \mathrm{p}$ value 0.000 ). This implies that one percentage change in stakeholder involvement effectiveness is associated with 54.5 percentage change in strategic plan implementation.

Finally, the study findings indicated that resource allocation had a positive and significant relationship with strategic plan implementation (beta $=0.295, \mathrm{p}$ value, 0.004). This implies that an increase in resource allocation effectiveness by 1 unit leads to improved strategic plan implementation at a rate of 29.5 percent.

Table 7: Regression Coefficients

\begin{tabular}{lccccc}
\hline & \multicolumn{2}{c}{ Unstandardized Coefficients } & \multicolumn{3}{c}{ Standardized Coefficients } \\
Variable & B & Std. Error & Beta & t & Sig. \\
\hline (Constant) & -0.087 & 0.27 & & -0.322 & 0.748 \\
Transformational Leadership & 0.154 & 0.068 & 0.199 & 2.264 & 0.026 \\
Stakeholder Involvement & 0.545 & 0.128 & 0.467 & 4.241 & 0.000 \\
Resource Allocation & 0.295 & 0.101 & 0.268 & 2.929 & 0.004 \\
\hline
\end{tabular}

a Dependent Variable: Strategy Implementation

\section{Conclusions}

Transformational leadership was statistically significant in explaining strategic plan implementation. The banking institution has applied a transformational leadership style in the day-to-day running of the institution. Maintenance of a policy manual is necessary in the sector and needs regular updates to be up-to-date with the dynamic changes in the sector this will help in making strategic decisions. These changes have also been found to be influenced by the environment and they have an effect on realization of goals. The skills adopted by the leaders not only affect realization of goals but also influences employee's performance. Co-operative bank needs to communicate their vision, mission in order to facilitate achievement of sufficient results.

Stakeholder involvement was statistically significant in explaining strategic plan implementation in cooperative bank. The study concluded that it is very vital to ensure the stakeholders are involved in strategic plan formulation and implementation for the brainstorming on ideas. The study concludes that the ways of promoting strategic plan ownership and sustainability by the stakeholders should include: formulation and implementation processes which satisfy all and stakeholders, paying attention to stakeholders in order to satisfy those involved or affected, and ensuring maximum participation of all the stakeholders. The study found that it is very important to have in place adequate mechanisms of incorporating the views of stakeholders especially the ones that will be affected directly with the implementation of some of strategies this is because failure to incorporate their views 
the strategy implementation may fail due to resistance.

The study found that resource allocation was statistically significant in explaining strategic plan implementation. The study therefore concludes that resources availability and allocation is critical in ensuring successful implementation of strategic plan. This is because a lot of finances, human resources and infrastructural resources, technological resources are needed to ensure successful implementation. The study concludes that without these resources the firm will not be able to implement strategies to enhance revenue collection. The institution is focused towards ensuring its strategies are implemented and to facilitate that a budget for the process exists. Leadership commitment is vital in order to effectively monitor resources in order to facilitate positive results. Teams need to adhere to the budget as an evaluation and control tool to meet the set deadlines. Institutions also need to adopt innovative IT strategies and e-business to guarantee improved competitiveness in the sector.

\section{Recommendations}

The study recommends that the leadership of any organization should always stay visionary as this would help in steering the organization to attaining both its short and long-term goals. Organizational leaders should define the vision and of the institution. The rest of the members should be informed off all that necessary for them to be able to perform them to be able to perform their duties. Leaders should themselves lead with integrity-They should inspire their team members and be role models to promote successful implementation.

The bank should ensure that their policy manual is maintained and updated regularly, the institution also need to have in place policies to help guide the firm to overcome dynamic changes in the sector. The institution needs to employ skilled employee in order to facilitate realization of goals. The firm needs to have an effective communication process between managers and subordinates and vice versa, this would ensure sufficient results are well articulated and achieved.

The study recommends that the management should continuously assess stakeholder interests; this will help to promote their buy-in and eliminate intergroup conflicts thereby improving strategic plan implementation. The study also recommends that stakeholders should be included in all pre-implementation and inception meetings as well as their views being incorporated in planning and execution. This will increase the acceptability and ownership as well as enriching the strategic plan with more ideas.

The institution needs to put aside enough funds that would ensure a successful strategy implementation process. However, proper mechanisms should be put in place to ensure that the funds are used for the intended purpose. Where applicable the institutions should adopt innovative IT strategies and e-business to enhance competitiveness of the firm in the dynamic sector.

\section{References}

Abok, A. (2015). Factors Affecting Effective Implementation of Strategic Plans in Non- Governmental Organizations in Kenya. Retrieved on 30th April 2019 from http://ir.jkuat.ac.ke:8080/bitstream.

Akinyele S. T. \& Fasogbon O. I.(2007). Impact of Strategic Planning on Organizational Performance and Survival Research, Journal of Business Management, 1 (1), 62-71

Allio, M. K. (2005). A Short, Practical Guide to Implementing Strategy. Journal of Business Strategy, 26.

Atkinson, H. (2006). Strategy implementation: a role for the balanced scorecard? Management Decision, Vol. 44 (10), $1441-1460$.

Austin, W. J. (2002). Strategic planning for smart leadership. Stillwater, OK: New Forums Press.

Awward, A. (2008). The link between competitive priorities and competitive advantage. Paper Presented at the POMS $19^{\text {th }}$ Annual Conference, La Jolla, California, USA from May 9-12, 2008

Baden-Fuller, C. and Volberda, H.W. (1997). Strategic Renewal: How Large Complex Organizations Prepare for the Future, International Studies of Management \& Organization, 27(2): 95-120.

Bonoma, T.V. (1984). Making Your Marketing Strategies Work, Harvard Business Review, March/April, 62: 69-76

Chepkirui, C. (2012). The role of strategic leadership in strategy implementation at the Agricultural Development Corporation (ADC) in Kenya (Doctoral dissertation, University of Nairobi, Kenya).

Chepkoech, C. \& Waiganjo, E. W. (2015). Role of stakeholders in the implementation of strategic change in commercial banks in Kenya: A case study of National Bank of Kenya Limited. International Academic Journal of Human Resource and Business Administration, 1(5), 55-82.

Cooper, D.R.\& Schindler, P.S. (2011). Business Research Methods, $11^{\text {th }}$, ed. McGraw-Hill Publishing, Co. Ltd.New Delhi-India.

Creswell, J.W. (2013) Qualitative Inquiry and Research Design: Choosing among Five Approaches, 3rd edition, Thousand Oaks, CA: Sage,

D’Aveni, R. (1994). Hypercompetition: managing the dynamics of strategic maneuvering. Free Press, New York Drazin,R. \& Howard, P. (1984), Strategy implementation: a technique for organizational design, Journal of 
Management Studies, Vol. 34 No.3, pp.465-85.

Gaya, H., Struwig, M. \& Smith, E. (2013). Creating a sustainable competitive advantage at a high performing firm in Kenya. African journal of business management, 7(21), 2049.

Hauc, A. \& Kovac, J. (2000). Project Management in Strategy Execution - Experiences in Slovenia, International Journal of Project Management, 18: 61-67.

Hitt, M., Freeman, R. \& Harrison, J. (2001). The Blackwell Handbook of Strategic Management. Hoboken, NJ: Wiley- Blackwell Publishers Ltd.

Hrebiniak, L. (2006). Obstacles to Effecitive Strategy Implementation. Organizational Dynamics, 35(1), 12-31.

Huang, H. I. (2012). An empirical analysis of the strategic management of competitive advantage: a case study of higher technical and vocational education in Taiwan (Doctoral dissertation, Victoria University).

Hussey, D. (1996). The Execution Challenge, Chichester: Wiley \& Sons Schilit, W.K. (1987) An Examination of the Influence of Middle-Level Managers in Formulating and Implementing Strategic Decisions, Journal of Management Studies, 24(3): 271-293.

Karimi S. W. (2015). Challenges of Strategic Implementation in Mathare 4A Slum Upgrading in Nairobi. $A n$ Unpublished MBA Project. Nairobi : University of Nairobi.

Kothari, C.R. (2012). Research methodology: Methods and techniques. Revised 2nd edition. New age international publishers, New Delhi

Kristie L. (2018). What is Strategy Implementation/ Updated June 30,Kristie Lorette; Updated June 30, 2018

Mathur, V., Price, A. \& Ali, S. (2008). Conceptualizing stakeholder engagement in the context of sustainability and its assessment. Journal of Construction Management and Economics, 26(6): 601-609.

Muchai, O. F. (20111). Influence of corporate culture on strategy implementation within commercial banks of Kenya. An Unpublished MBA Project. Nairobi : University of Nairobi.

Ndung'u, W. C., Machuki, V. N., \& Murerwa, T. (2014). Response Strategies by Commercial Banks to Economic Changes in Kenya. Journal of Economics and Sustainable Development, 5(2): 137-153

Nnamani E., Ejim E.P. \& Ozobu A.(2015). Effect of Strategy Formulation on Organizational Performance: A Study of Innoson Manufacturing Company Ltd Emene, Enugu World. Journal of Management and Behavioral Studies, 3 (1), 09-20.

Noble, C.H. (1999). "Building the Strategy Implementation Network". Business Horizons, 19-27.

Nutt, P. C. (1998). Surprising but true: half the decisions in organizations fail. Academy of Management Executive, 13/4, 75 - 90.

Nyaga, C. M. (2012). Strategy implementation as a key success factor in mobile telecommunications in Kenya. An Unpublished MBA Project. Nairobi : University of Nairobi.

Organization for Economic Cooperation and Development (OECD) (2001). Guidelines for Multinational Enterprises www.oecd.org/daf/investment/guidelines

Oslon, E. M., Slatter, S. F., \& Hult, G. T. (2005). The importance of structure and process to Strategy Implementation, Business Horizons, 48, 47-54

Pearce, J. A. II, Robinson, R. J. Jr, \&Amital M. (2007): Strategic Management: Formulation, Implementation and Control.McGraw-Hill, 10th Edition.

Porter, M.E. (2005). "Competitive Strategy", Translated by: J. Majidi\& A. Mehrpooya, Rasa Published, Tehran, 2005.

Rajasekar, J. (2014). Factors affecting Effective Strategy Implementation in a Service Industry: A Study of Electricity Distribution Companies in the Sultanate of Oman. International Journal of Business and Social Science, 5(9).

Schaap, J. I. (2012). Toward strategy implementation success: An empirical study of the role of senior-level leaders in the Nevada gaming industry. UNLV Gaming Research \& Review Journal, 10(2), 2.

Schilit, W.K. (1987) An Examination of the Influence of Middle-Level Managers in Formulating and Implementing Strategic Decisions, Journal of Management Studies, 24(3): 271-293.

Shamila, N. K. , Muhammad, Z.T. \& Sohail, Z .(2016). Strategy formulation, strategy content and performance: empirical evidence from private sector organizations in Pakistan. Pakistan Business Review, 7(1), 357-376.

Sharma, S. \& Starik, M. (2004). Stakeholders, the Environment and Society. Cheltenham: Edward Elgar.

Sila, H. M. \& Gichinga, L. (2016). Role of Strategic Leadership on Strategy Implementation in Public Universities in Kenya- A Case Study of JKUAT Main Campus. International Journal of Innovative Research, 5(6), 216-239.

Thomas, L.C. (2002). The Nature and Dynamics of Counter-Execution in Strategic Marketing: A Propositional Inventory, Journal of Strategic Marketing, 10: 189-204.

Volberda, H. W. (1996) Toward the fl exible form: how to remain vital in hypercompetitive environments. Organ Sci 7(4):359

Zona, F. \& Zattoni, A. (2005). Beyond the black box of demography: Board processes and task effectiveness within Italian firms. Corporate Governance: An International Review, 15, 852-864 